\title{
AVALIAÇÃO DA ATIVIDADE ANTIOXIDANTE DA ESPÉCIE Chamissoa altissima
}

\section{Heloina Nathalliê Mariano da Silva' \\ Marcos J. Salvador ${ }^{2}$ \\ Wallace Ribeiro Corrêa ${ }^{3}$}

Resumo: A oxidação é um processo natural no metabolismo humano, o que produz radicais livres, que estão envolvidos em diversas reações biológicas. No entanto, se a produção de radicais livres supera a capacidade antioxidante em um sistema vivo, várias patologias podem ser desencadeadas. Para impedir esse dano, pesquisas tem dado atenção a produtos naturais que apresentem capacidade antioxidantes, como é o caso das plantas pertencentes à família Amaranthaceae, que se destacam pela produção de componentes fenólicos. Assim, o presente estudo teve por objetivo avaliar a capacidade antioxidante dos extratos da espécie Chamissoa altissima, através dos métodos de DPPH, ORACFL e, Folin Ciocalteu. Os resultados evidenciaram que o extrato bruto etanólico da espécie apresenta boa atividade antioxidante, com valores entre $\left(I C_{50}=108.45\right.$ no DPPH) e $(3049.27 \mu \mathrm{mol} T E / g$, no ORACFL) podendo correlacionar a atividade antioxidante ao nível de compostos fenólicos totais (1.31 mg GAE/g).

Palavras-chave: Família Amaranthaceae; Chamissoa altissima; Atividade biológicas; Radicais livres.

1 Departamento de Desenvolvimento Educacional/IFSULDEMINAS, Inconfidentes, MG, Brasil. E-mail: heloinanatalie@hotmail.com.

${ }^{2}$ Curso de Farmácia, Departamento de Biologia Vegetal, Instituto de Biologia, UNICAMP - Campinas, SP, Brasil. E-mail: marcosjs@unicamp.br.

3 Departamento de Desenvolvimento Educacional/IFSULDEMINAS, Inconfidentes, MG, Brasil. E-mail: crwallace@bol.com.br. 